\title{
Earthworks and pavements for the new international airport for Kuala Lumpur
}

\author{
by \\ H. G. Skepper, M.B.E., B.Sc., M.I.C.E., \\ H. Rook, M.B.E., B.Sc., D.I.C., A.M.I.C.E. \\ and \\ W. H. Ting, B.E., M.S., A.M.I.C.E.
}

\begin{abstract}
AUTHORS' PRESENTATION
The Authors said that the airport was sited in the only possible place within 15 miles of Kuala Lumpur which had obstruction-free approaches. The threshold levels adopted allowed for an approach plane of 1 in 100 for the first $1000 \mathrm{ft}$ from the threshold and 1 in 66 thereafter. The threshold levels themselves were determined by the level of the road to Sungei Buloh village in the north and the low-lying hills of the rubber plantations in the south. To economize in earthworks the runway was constructed having a falling gradient from the south of 1 in 200 and a rising gradient to the north, from approximately mid-way along the runway, of 1 in 600 .

88. The drainage system for the airport was designed to accommodate a rainfall density of $6 \mathrm{in}$./h during a $20 \mathrm{~min}$ storm. As the Airport complex was located in the watershed of the Sungei Damansara the storm water had to be collected on the western side of the airport and channelled beneath the flight strip to be discharged into the Sungei Damansara. Since the water from the Sungei Damansara was being used as a source of supply to Kuala Lumpur it was necessary to install kerosene interceptors to the two main parking aprons.

89. From the borehole samples and initial earthwork cuttings it was thought that the soils could be reasonably identified by their colour and vertical distribution which were described in the Paper. Laboratory and field tests were also carried out on the soils to establish their strength characteristics, uses as construction materials, and the amount of lime necessary for their stabilization. When evaluating the strength of the finished pavements by the plate-bearing method it was observed that the relation between the deflexion of the plate and the log of the number of repetitions was not linear. The normal method of obtaining the 1.c.n. at 10000 repetitions could not be applied and it was decided to interpret the results by the method used by F. R. Martin."
\end{abstract}

90. One of the main reasons for the quite reasonable price obtained for the airport pavement was the use of locally available cheap materials. Preliminary tests were carried out on these materials and the results of the tests were given to the tenderers who were asked to satisfy themselves, by additional testing, of the suitability of the materials for the type of pavement specified. The tenderers in effect had to design the bitumen-bound base before tendering and submit their designs with their tenders. The epoxy resin bitumen surface dressing was applied to render the apron fuel proof.

91. They wished to make the following corrections to the Paper. In $\S 13$ the reference should be to soils of Types 2 and 3, not 1 and 2. In Fig. 5 the symbols 
referred to compaction and not to grading, and should have been between the columns 'Passing' and 'Blows', separated from the former. In Fig. 7 the dots in the first curve represented the laboratory B.S. heavy compaction. The scale below Fig. 10 represented percentage compaction. In Fig. 16, the graphs should be read in the order (1) Monthly rainfall; (2) Earthworks--excavated volume and excavated volume $\times$ haul; (3) Earthworks - paved area compaction; (4) Preparation of formation; (5) Stabilized soil; and (6) Asphalt pavement. In addition the key of the second graph required correction: the area enclosed by a broken line represented cu. $y d x$ $\mathrm{yd} \times 10^{8}$ and not cu. yd $\times$ sq. $\mathrm{yd} \times 10^{8}$.

Dr R. S. Millard (Road Research Laboratory) said that this was not a very exceptional job, except possibly in regard to the rainfall of about $100 \mathrm{in}$./year. The virtues of the work were those of sound and careful engineering, taking full advantage of modern knowledge and techniques. First of all, there was the full exploitation of the potentiality of the local materials, the careful classification and use of the soils found on site for filling and in soil stabilization, and the use of the local mining sand and aggregates in the bituminous mixtures.

93. The pavement was not only well designed for its structural adequacy with reasonable economy, but also in its use of construction methods well adapted to the wet climate.

94. Mr Skepper had stated that they had no difficulty in consistently compacting soil to a relative density of $95 \%$ modified AASHO. Those who worked in Britain would perhaps be more familiar with specification by air voids. This figure meant that the soil was consistently compacted to between 3 and $7 \%$ air voids. Thus the soil was extremely well compacted, providing a sub-grade of high bearing capacity, equivalent, as tests showed, to about $30 \%$ CBR. Perhaps the Authors would provide more information about control of compaction. For instance, what were the criteria used in deciding when to start work on the earthworks and on the trimming after rain? How, in detail, did the weather affect earthworks? The Authors had given a histogram: could they state how output in working hours per month was related to rainfall?

95. The Authors had adopted a design CBR of $10 \%$ for the pavement which might be considered somewhat conservative. They had not said how deep the watertable was, but on the assumption that it was at least $10 \mathrm{ft}$ below formation level, the critical moisture conditions were those at the time of construction of the runway and, as Fig. 5 showed, the CBR value appropriate to $95 \%$ modified AASHO compaction ranged between $30 \%$ and $40 \%$. There was some corroboration of this in the field CBR measurements in Table 4 . The figure of 14.3 in the table needed explaining, but the rest were between 27 and 49 . Could the Authors say whether there was something more than native caution in their choice of $10 \%$ ? There was a fair amount of evidence that a higher figure could have been used.

96. The 4 in. of lime-stabilized sub-base provided also an adequate working platform. On the design strengths obtained, at least the lowest 4 in. of bituminous base could also have been made of cheaper stabilized soil. The designers considered a stabilized soil base but decided against it because of possible difficulties in bad weather. In the event, wet weather seemed to have proved less of a hindrance to the stabilization than was expected. With the experience behind them of the stabilized sub-base, would the Authors now modify their reservations on its use as part of the base?

97. The asphalt base contained only $3.3 \%$ of bitumen with some $7 \%$ voids. This material could not have been impermeable and it was likely that some of the 100 in. of rain per year penetrated it during construction. With voids in the region of $7 \%$, the bituminous base could have contained up to 4 gallons of water per square yard. Could the Authors state whether water did collect in the base during construction, and, if so, what arrangements were made to drain it away? Certainly one advantage of the lime-stabilized sub-base was that it protected the soil from being weakened by 
this water. Had it been laid on moisture-susceptible material there might well have been trouble.

Mr F. R. Martin (Ministry of Public Building and Works) said that he would confine his remarks to the load classification number system. This was developed by the Air Ministry Works Directorate, how merged into the Directorate General of Works of the MPBW, and accepted by ICAO as one of the two acceptable international systems of airfield and aircraft classification. It had not been modified by the test results given by him in 1957, which were of a very experimental nature. The Authors stated in $\S 71$ that the ICAO system was the one used in evaluating the pavement strengths, but the results given in the Paper did not seem to follow the normally accepted procedures for l.c.n. assessment. These procedures would allow for repetitional loadings to have been carried out at loads giving deflexions of 0.05 in. and $0.10 \mathrm{in}$, and normally these deflexions resulted in 1.c.n. assessments being obtained. By taking the loading beyond these deflexions to $0.15 \mathrm{in}$. and $0.20 \mathrm{in}$., the pavement appeared to have been overstressed by the repetitional test loads, and the steeply rising curves of Fig. 15 showed this to be the case.

99. On all except very old flexible pavements they had found that the first two load repetitions did not necessarily fall in the straight line which could be drawn through the third and subsequent points.

100. Always on newer asphalt - and this was the type being tested-there was a tendency for a gradual curve to be shown for the higher loadings, particularly when a deflexion of more than about 0.15 in. was obtained. In these cases a straight line drawn through the third, fourth and fifth points would allow an acceptable evaluation to be made. Extended repetition tests had shown this assumption to be justified. It must not be forgotten that the loadings involved at these higher deflexions were often greater than the evaluated safe load for the pavement and also that the load repetitions were concentrated into a few hours compared with the years needed to have the same effect achieved in practice.

101. There was another very rough-and-ready rule developed over the years, which indicated that when there were deflexions differing by about 0.006 in. on repetitional loading, no further repetitional loads were applied. It had been found from many hundreds of tests that loads giving deflexions beyond this produced uncertain 1.c.n. assessments. Would the Authors give the full testing details for examination, since this pavement was unique in its construction and details of the tests carried out would be valuable when considering possible future pavement designs of this kind? Nowhere else was there a pavement which included 16 in. of Marshall asphalt in its make-up, all laid at the same time.

102. It was not surprising that the addition of the asphalt wearing course referred to in $\$ 75$ did not affect the 1.c.n. assessment of the pavement obtained at the top level of the base course. Any deflexion in the thin dense wearing course itself would contribute very little to the overall deflexion of the rest of the pavement, and it was the relationship of loads to overall pavement deflexions upon which the 1.c.n. system was based. Likewise, additional rolling or relatively light trafficking with contractors' vehicles on dense surfacing properly laid and compacted when hot would achieve nothing, and this was borne out by the comments in $\S 78$.

103. The strengthening of pavements with age, referred to in $\S 77$, was recognized with cement-bound materials and was reasonably well understood and allowed for both at the design and testing stages. With bitumen-bound materials there was also an age/strength relationship, less well understood and probably not showing any increase beyond 1-2 years. This had been found from many tests on pavements of all ages. Plate-testing would not normally be undertaken on asphalts less than several months old in the United Kingdom, and older in tropical climates.

104. The findings of the Authors on an age/strength relationship given in Table 6 were of interest but Mr Martin questioned the significance of the results, which had 
standard deviations of about $30 \%$ of the average values for a relatively small number of tests.

105. Could the Authors say if the effect of the sun on the lattice beam cantilever datum for the test instruments was taken into account when carrying out their tests? He had found that this could have an appreciable effect, particularly in hot climates.

106. Tables 4 and 6 gave the results of l.c.n. testing used for control purposes during the construction of the pavements. This was an extension of the 1.c.n. system which should not be promoted for other than purely experimental purposes. If plate-testing were required for control reasons the tests should be on smaller plates, say 12 in. or 15 in. in diameter, and loads/residual settlements used for comparison purposes. The more usual density and strength controls should have been sufficient.

Mr H. Jennings (Civil Engineering Laboratory, Royal Air Force, Cardington) congratulated the Authors on the production of a most interesting Paper.

108. Although the bitumen-bound base was reported as containing $45 \%$ granite aggregate A, the coarse sand B contained an appreciable amount of gravel, and the overall coarse aggregate content appeared to have been of the order of $58 \%$. Nevertheless, the design binder content of 3.3\% seemed unduly low and $\mathrm{Mr}$ Jennings was doubtful of the validity of the reduction from $3.7 \%$ to $3.3 \%$ to allow for the amount of coarse aggregate retained on a 1 in. sieve. He believed that in the MPBW General Specification a more satisfactory design method had been developed, in which (at the design stage) the amount of aggregate retained on the 1 in. sieve was replaced by an equal amount of aggregate passing the 1 in. sieve and retained on the $\frac{3}{7}$ in. sieve. This had been found very satisfactory in practice and no adjustment to the mean optimum binder content was required.

109. In the case of Kuala Lumpur, the effect of the reduction of binder content to $3.2 \%$ was to lower the density of the moulded specimens drastically. Reference to the curve for density in relation to binder content given in Fig. 2 of a paper by Mr Rook ${ }^{5}$ showed that at $3 \cdot 2 \%$ the density was well down the curve on the dry side. Reference to Table 5 showed that the mean control density was in excess of the j.s.m. density indicating that the latter was probably unduly low. It would be interesting to know how the mean control density compared with $94 \%$ of the theoretical density -surely a more appropriate yardstick for material containing retained $1 \mathrm{in}$. aggregate. In spite of this indication that considerable care and attention was given to the compaction of this material in the field, it was Mr Jennings's view that the increase in deflexion under the $18 \mathrm{in}$. plate, when the number of loadings was increased from 10 to 100 (see Fig. 15 of the Paper) probably represented, in part at least, some densification of the bitumen-bound base.

110. He asked why such a low stability as $650 \mathrm{lb}$ was specified. A design minimum of 1500 with a field control minimum of 1200 would surely have been more appropriate for this class of material and would have represented a more reasonable step down from the high stability of the surfacing. In the event, the stability of the mixture was not in question, but it made the specified figure look far too low.

111. The material used for the binder or base course seemed to have been very good but the design method differed from the MPBW method in two significant respects. One was the arbitrary reduction in binder content to allow for the aggregate retained on a $1 \mathrm{in}$. sieve (already referred to in connexion with the bitumen-bound base): the other was the figure of 5-7\% specified for total voids. It had been found in practice that the voids in the base course tended to be rather lower than those in the wearing course (which one would expect from a study of the respective aggregate gradation charts) and at the MPBW these were specified at the design stage at from 3-5\% for the base course, with appropriate adjustments to the 'voids filled with binder'. The MPBW therefore designed to a slightly higher binder content and did not reduce this to allow for aggregate retained on a 1 in. sieve.

112. The design curves for the binder content ${ }^{5}$ showed that the designed bitumen 
content of $4.20 \%$ was well below peak density on the dry side. On the basis of the values given in the figure referred to, ${ }^{5} \mathrm{Mr}$ Jennings would have designed the mix on a mean optimum binder content of $5 \%$ at which the mould density would have been just above $148 \mathrm{lb} / \mathrm{cu}$. $\mathrm{ft}$. As in the case of the bitumen-bound base, careful attention to rolling had produced good compaction in the field, the control average being equivalent to $95 \%$ of theoretical density against the $94 \%$ specified.

113. Turning to the wearing course, the job standard mix had a rather high flow at $15 \cdot 1$. Mr Jennings wondered whether this was partly the result of the coarse aggregate grading which (Fig. 14 of the Paper) appeared to be deficient in material passing a $\frac{3}{4}$ in. and retained on a $\frac{1}{2}$ in. sieve. This high flow would also contribute to the deformation recorded under the plate-loading test. His only other comment concerned the field density of the wearing course, the control average of which was low at just over $96.5 \%$ of j.s.m. density. In the MPBW much consideration had been given to the question of field density, particularly in relation to wearing-course mixtures which, being laid to a nominal thickness of about $1 \frac{1}{2}$ in., cooled relatively quickly and were therefore more difficult to compact than base courses.

114. As a result of a study of many contracts they had now produced a specification which applied a simplified statistical control to compaction. This specified that twin samples should be taken from every 1000 sq. yd of each course and that the mean value of the density of these two samples should be taken as the field density. It was further specified that of twenty consecutive mean values, not more than three results were to be below the specified density. From experience it was known that this required a mean value (for all test results) of approximately $99 \%$ of j.s.m. density. In order to ensure that the right technique was developed the specification required the contractor to achieve $99 \%$ compaction in the trial strip before the main work got under way.

115. Table 7 showed the test results for binder content and field compaction (probably the two most important criteria for an asphalt pavement) for Kuala Lumpur and four MPBW airfield pavements, two of which were completed in 1965 and two

TABle 7: Marshall asphalt Wearing COURSE

\begin{tabular}{|c|c|c|c|c|c|c|}
\hline \multirow[t]{2}{*}{ Airfield } & \multicolumn{3}{|c|}{ Binder content } & \multicolumn{3}{|c|}{$\begin{array}{c}\% \text { Compaction } \\
\text { Field density } / \\
\text { job standard mix density }\end{array}$} \\
\hline & Specified & $\mid \begin{array}{c}\text { Control } \\
\text { mean }\end{array}$ & $\begin{array}{l}\text { Standard } \\
\text { deviation }\end{array}$ & Specified & $\left|\begin{array}{c}\text { Control } \\
\text { mean }\end{array}\right|$ & $\begin{array}{l}\text { Standard } \\
\text { deviation }\end{array}$ \\
\hline $\begin{array}{l}\text { Kuala Lumpur . } \\
\text { (100 Test results) }\end{array}$ & $5 \cdot 4$ & $5 \cdot 37$ & $0 \cdot 19$ & $\underset{98}{\operatorname{Min}}$ & $96 \cdot 5$ & $1 \cdot 76$ \\
\hline $\begin{array}{l}\text { Task No. } 1306(1965) \\
\text { (28 Test results) }\end{array}$ & $5 \cdot 6$ & $5 \cdot 59$ & $0 \cdot 17$ & $98^{*}$ & 98.7 & 0.81 \\
\hline $\begin{array}{l}\text { Task No. } 1145(1965) \\
\text { (42 Test results) }\end{array}$ & $5 \cdot 3$ & $5 \cdot 2$ & $0 \cdot 18$ & $98^{*}$ & $98 \cdot 2$ & $1 \cdot 02$ \\
\hline $\begin{array}{c}\text { Task No. } 1844(1966) \\
\text { (20 Test results). }\end{array}$ & $5 \cdot 7$ & $5 \cdot 58$ & 0.23 & $98^{*}$ & $98 \cdot 2$ & $1 \cdot 32$ \\
\hline $\begin{array}{l}\text { Task No. } 1692(1966) \\
(59 \text { Test results) }\end{array}$ & $5 \cdot 2$ & 5.04 & 0.18 & $98^{*}$ & 98.9 & 0.94 \\
\hline
\end{tabular}

* Specification:-Not more than three in twenty consecutive results to be below $98 \%$. 
in 1966. The last contract was up to the highest standards of control which could normally be expected.

Mr J. C. Finnigan (Ministry of Public Buildings and Works) said that his remarks would be confined to the California Bearing Ratio of the soils and in particular to the results published in Table 1 . These were fairly widely scattered. This could presumably be accounted for by an equally wide variation in the character of the soils tested, but there appeared to be no relationship between moisture content and plasticity with the CBR, which was strange considering that the samples tested apparently all belonged to the same family of soils. Was there any reasonable explanation for this?

117. The CBR figures themselves gave cause for comment. For instance, these indicated that the soil, after soaking, retained a very high percentage of its 'optimum' CBR strength. This would not be unusual in a graded granular type of material with a relatively low fines content $(20 \%$ or less for a sandy soil) but in fact this soil possessed a relatively high fines content $(50-60 \%)$. He could find no similar case of such a high residual strength of the soil after soaking. The nearest he could find in his own experience was a soil tested from Hong Kong. It was very similar in mode of occurrence, in that it was derived from residual weathering of granite. The grading and plasticity were similar. In fact, the Hong Kong soil had a plasticity limit of 22; the samples at Kuala Lumpur were between 25 and 40 . The amount of fines of the Hong Kong soil was $52 \%$; at Kuala Lumpur they were $51-59 \%$. The most important fact was that the CBR of the Hong Kong soil was about 42 for optimum moisture content, and the mean figure given in Table 1 was a similar CBR of about 35.

118. What was surprising was that the mean soaked CBR of the Kuala Lumpur soils was 21 , whereas in the Hong Kong soil the figure was only 1 : in other words, there was very little strength after soaking, which one would normally expect with soil of such high fines content.

119. In the same context he wished to comment on a point raised by Dr Millard, that for the design CBR a figure of $10 \mathrm{might}$ be considered as being conservative. Dr Millard had referred to the in situ CBR's of 27-49. These figures were for the material after it was laid, and compacted, and not in the soaked condition. In fact the mean soaked CBR from the figures given in Table 1 was 12 and not 10 but both of the values, the 10 and the 12 , appeared to him to be relatively high for a soil of this particular type and not as Dr Millard maintained, conservative.

Mr J. Mitchell (Ministry of Public Buildings and Works) said that the Authors had produced a very interesting Paper.

121. The MPBW had constructed many Marshall asphalt pavements in the UK and overseas to withstand tire pressures up to $330 \mathrm{lb} / \mathrm{sq}$. in. However, they had not yet used a depth of new Marshall asphalt greater than $10 \mathrm{in}$., probably because rolled dry lean concrete, graded stone and cement-stabilized soil had been more economical for the sites being considered. Rolled dry lean concrete and cement-stabilized soils had disadvantages in giving high thermal stresses in pavement construction unless their strengths were limited. The deep asphalt construction described by the Authors appeared to eliminate the thermal stresses and the cracks which were a bugbear to everyone connected with pavements.

122. With reference to $\S 6$, could the Authors give details of how 16 in. was found to be the critical depth in calculating the effects of the equivalent single wheel load for tire pressures of $250 \mathrm{lb} / \mathrm{sq}$. in. and why below $16 \mathrm{in}$. depth, $100 \mathrm{lb} / \mathrm{sq}$. in. was found to be more critical? Which types of aircraft were considered and were the equivalent single wheel loads calculated by the l.c.n. method or were they influenced by the curves produced by Burmister in 1943 ?

123. Fig. 6 gave a cross section through the runway. Could details be given of the transverse gradients? The MPBW had found with the heavy rainfall in Malaya, 
that this was very important indeed, especially with the present problems of aquaplaning.

124. With regard to $\S 26$, it was noted that a concrete pavement was considered to be more expensive than asphalt. Could the Authors give the cost per ton of bitumen and cement respectively? The MPBW normally designed for a minimum of $300 \mathrm{ft}$ of concrete surface at each end of the runway to resist fuel spillage, jet-engine blast effects, scuffing of tires and the high vibrating loads of standing aircraft. The design for l.c.n. 100 would probably have been a 16 in. thick concrete slab on a foundation with a $k$ value of 300 . Was concrete considered for the runway ends or were they treated with fuel and heat resisting material? If so, had the friction values of the treated surfaces been satisfactory?

125. With regard to $\$ 27$, the experiments with epoxy compounds for surface dressing of bituminous surfaces, as applied to fuel spillage areas, appeared to have been very thorough. Could details be given on whether these materials were being marketed under a trade name in the UK and overseas?

126. It was recommended in $\S 35$ that the ideal speed of the tamping roller should be approximately $15 \mathrm{miles} / \mathrm{h}$ and with Type 1 soil the roller travelled at about $11 \mathrm{miles} / \mathrm{h}$ and was still reasonably efficient. These appeared to be unusually high speeds for compacting purposes.

127. It was implied in $\S 65$ that sand-stabilized soil was fractionally cheaper than lime-stabilized soil. Could the Authors give the relative cost per ton of lime and cement? It would also be interesting to know what type of kiln was used for producing lime on the site. Cement-stabilized soil appeared to have the advantage of gaining strength with time and also of being less susceptible to wet conditions. The Ministry had found that the use of a cement-bound layer in flexible construction generally increased the 1.c.n. considerably when compared with a similar thickness of bitumen-bound material. This the Authors had found in testing the slabs which had cement stabilization underneath compared with lime.

Mr G. M. Dormon (Shell International Petroleum Co. Ltd) said that he wished to comment briefly on the design and testing of the structure, which was of particular interest to his company since they had in recent years developed what they liked to think of as a rational approach to the design of flexible pavements for roads. This approach was based in the main on a knowledge of the dynamic elastic properties of the various construction materials in situ which had been obtained from extensive vibration tests over many years. These material data were used in conjunction with elastic theory for stress distribution in a multi-layer system, in order to obtain the distribution of stress throughout the structure. In principle, design was then effected by selecting the thicknesses of the various component layers in such a way that they were not overstressed under load. This overstressing could apply to the soil, the asphalt or the granular base material.

129. The extension of this approach for airports had been helped recently by the development of computer programs which could now handle any combination of multi-wheel assemblies and give the whole stress environment at any point in the structure. On this basis, design curves for aircraft could be drawn up similar to those for roads. From this aspect he would consider that the design at Kuala Lumpur was certainly adequate for fairly extensive loading conditions of current large civil aircraft, such as the Boeing 707, and, in fact, by comparison with design requirements for conventional granular-based flexible pavements, slightly conservative.

130. On the same basis it was found that the advantage of asphalt over granular base materials varied with the loading and the soil, and by comparison with conventional constructions the advantage was smaller as the soil became stronger. This would mean that if, as suggested by one speaker, the CBR of the soil were as high as 30 , there would be a very strong airfield on this site.

131. Using the approach outlined, the permissible stress levels were gauged by 
an analysis of airfield structures of proved performance. Such an analysis gave stress levels about $25 \%$ higher than would normally be experienced on heavily trafficked roads, and in general this would be equivalent to a trafficking factor of around 10-50.

132. One particular problem was to relate design on this basis to the more conventional design systems available for airfields, such as the widely used l.c.n. system. This was because the 1.c.n. system, as normally defined, was based on an empirical combination of permanent deformation and elastic deflexion, and the results had to be interpreted and guided by experience. In this connexion Mr Dormon suggested that a pavement such as that at Kuala Lumpur was neither rigid nor flexible in the conventional sense. It could afford advantages over either and there seemed to be no reason to suppose that the design criteria employed should be related specifically to experience with either rigid or conventional flexible pavements. This was already the situation, it seemed to him, in the 1.c.n. system, where the testing technique employed and the load classification numbers obtained were quite different for rigid pavements than for flexible pavements. Mr Dormon had been surprised to find that it was anticipated that this experience could be extended automatically to a pavement of this nature. On the other hand, it was possible, using an alternative definition of 1.c.n., i.e. the one to which Mr Rook referred (the load to give an elastic deflexion of 0.1 in.), to estimate theoretically the 1.c.n. of the pavement. A value of about 100 was obtained, which was not dissimilar to those given in the Paper.

133. Comments had been made on the fact that the deflexion/log repetitions of loading curve were not linear over an extensive range. This was not very surprising and Mr Martin had commented to this effect. Mr Dormon thought that interpretation of the results was made difficult by the creep liable to occur, particularly at high ambient temperatures in asphalt materials under heavy static loads, and if the l.c.n. test procedure were to be modified and adopted for this form of construction it would need to be extended to cover creep phenomena more precisely.

134. Another particular point of interest was the observed increase in l.c.n. with time. This had often been noticed and many factors might play a part, although oxidation of the binder as such would not be expected to be a primary cause, especially in dense mixes with void contents of less than $3 \%$. There could be some structural changes in the binder, but laboratory investigations suggested that it was the filler fraction of the mix which was of special importance in this connexion. The extent, however, to which such increases in 1.c.n. were related to changes of the binder filler system was not yet clear.

Mr R. D. Nutt (Brian Colquhoun \& Partners) referred first to the moisture content in the pavement. Dr Millard had already asked for details of the depth of the watertable. Did the Authors carry out any soil-suction tests and did they, subsequent to the construction of the pavement, find out the moisture content of the sub-soil?

136. Mr Nutt queried the figure of $650 \mathrm{lb}$ Marshall stability as being somewhat ow for the base and also queried whether sand, which appeared to be an indigenous material, could not have been used as opposed to an all-in aggregate. It had been said that the Contractor had been unable to meet the Specification with sand and had therefore used an all-in aggregate. From German and American published work on this subject, $670 \mathrm{lb} / \mathrm{sq}$. in. appeared to be a perfectly reasonable figure and experiments which Mr Nutt had carried out on extremely bad sands indicated that this was a low stability which should easily be obtained. He felt that it was surprising that the Contractor should not have been able to meet the Specification. The fact that he was not able to meet it with sand must have increased his cost very considerably indeed.

137. Mr Nutt asked what sort of roller and rolling techniques were used on the bitumen-bound base.

138. Why was Marshall asphalt chosen for the design criteria and not normal British Standard asphalt? Were aircraft exerting tire pressures in excess of $150 \mathrm{lb} /$ 
sq. in. envisaged? Was it in fact a military design airfield as well as a civil one, with Marshall asphalt for the two top layers?

139. On the question of 1.c.n. tests Mr Nutt supported Mr Martin, who hoped that the complete l.c.n. results would be published. He also asked what sort of recoveries were obtained on release of load. Mr Nutt would have expected that the 1.c.n. results would be lower than those obtained in Britain, one reason being the effect of temperature on testing. Would the Authors comment on this? Certainly his own experience had been that when the temperature rose, lower 1.c.n. results could be expected, but this depended a good deal on the design of the pavement in question.

140. It had been suggested that this was the first all-bitumen airport and was therefore unique. Mr Nutt could not find in the Paper the date on which work started. The airport had 16 in. of flexible construction on top of 4 in. of lime stabilization, making a total of 20 in. Abadan Airport had 20.5 in. of purely bituminous material; there was no lime or cement-stabilized material underneath, but a sand asphalt base was used. It was designed in 1956, construction started in 1958, and it was finished about 1961. Some very low l.c.n. results indeed were obtained. This was to be expected from the particular design, which was not related to British practice, in that this was a very flexible pavement indeed. All the aircraft which the airport was designed to take were checked in case any difficulties arose. There was nearly $100 \%$ elastic recovery when the load was released on the plate-loading tests, which was somewhat surprising, but confirmed that the pavement was acting as designed.

Mr F. W. Spencer (Scott, Wilson Kirkpatrick \& Partners) said that having some experience of Malaya himself he could well appreciate the difficulties with which the Authors had had to contend and which they had overcome.

142. With regard to the layout adopted for the airport, he noted that the terminal area had been located at the south-eastern extremity of the runway. This was an unusual and uneconomical configuration. The layout might be applicable if all takeoffs occurred from the SE but he assumed that this was not the case, and a very long taxi-out distance was involved for aircraft when the wind blew from the south.

143. It was possible to work out the optimum position for minimum taxi-ing distance by taking into account the frequency of winds from each direction, landing distances and the overall taxi-in and -out distances for the different types of aircraft likely to be involved.

144. The layout was fundamentally similar to Gatwick but in that case the designer had to take into account the proximity of the railway station and the necessity of having the terminal building alongside it. Presumably the Authors had good reasons for planning in the manner chosen. It would be of interest if these reasons could be described.

145. In addition, the area available for future development of the apron appeared to be somewhat limited. Space was reserved for an additional three stands only and any requirement beyond this would seem to necessitate extending to the NE, which would put the additional stands some distance from the terminal building.

146. He would have thought that in this particular case a longer finger would have been better, giving three parking positions on each side rather than two. This would have provided greater apron depth and improved possibilities for future development.

147. The description of plate-loading tests up to 100 repetitions was of importance and in view of the results obtained it was desirable that the basis of the current theory should be examined.

148. One of the earliest references to the subject of repetitional loading occurred in 1949 in a paper by McLeod. ${ }^{6}$ In this paper the author reported the results of extensive plate-bearing tests carried out at various Canadian aerodromes and from 
these he developed relationships for loads, contact areas, deflexions and load repetitions extended to $10,100,1000$ and 10000 repetitions.

149. Whether or not McLeod actually conducted tests over this range of repetitions was not clear. He had stated that generally individual load tests were limited to six repetitions and he did make the point that a straight line extension of the deflexion readings from 6 to 10 repetitions on a semi-log graph led to only negligible error. He must therefore have been aware of the larger errors which might arise by extending to, say, 10000 repetitions. In this connexion it must be remembered that the formula for pavement design developed by McLeod was based on the load at 10 repetitions and presumably, therefore, he might have thought it unnecessary to draw attention to errors caused by a straight line extension of deflexion readings beyond this point.

150. However, the principle of extending these deflexion and settlement readings up to 10000 repetitions was at about the same time adopted by the Air Ministry Works Directorate and typical graphs based on the Air Ministry method continued to be illustrated in the current ICAO Aerodrome Manual. ${ }^{7}$ In a recent paper by Skinner it was stated that 'the method is based on the fact that the rate of increase in settlement resulting from repeated applications of the load decreases logarithmically.' Presumably, therefore, the Air Ministry must have conducted tests which would support that statement, because Mr Skinner was at the time in charge of the department concerned in the Air Ministry. As the repetitional loading aspect was of great importance, and the Authors' findings cast doubt on current practice, it would be helpful to have explained exactly on what basis these earlier statements had been made, and what evidence there was to support the theory.

Mr D. W. Turner (British Airports Authority) said that the design of the pavement was based on a CBR of $10 \%$, from which the Burmister method gave a thickness in deep asphalt of 16 in. In the event, a further 4 in. of pavement was provided, using a stabilized soil sub-base which the Authors described as a working course. Despite this additional 4 in., the resultant l.c.n. of the pavement after nine months appeared to be only just above the design figure. Subtracting one standard deviation, it was about 102. The effect of the stabilized sub-base on the l.c.n. was recognized by the Authors when they referred to the relationship between cement and lime as the stabilizing agent. Could it therefore be assumed that without the 4 in. stabilized sub-base the design 1.c.n. figure of 100 would not in fact have been achieved? $\mathrm{Mr}$ Turner found it difficult to conclude that the reduced pavement thickness had been justified and that the design in fact had been proved.

152. He wished to add his congratulations to those of others on the manner in which the work was carried out, particularly regarding the stabilization and the way in which the wet weather conditions were overcome. He also agreed with Mr Rook who had said that if any moral should be drawn, it was the proper use of local materials. But in this context one would not have said that the limestone, which had to be hauled 25 miles, was a local material. The materials immediately available were the sands and soils, and had more stabilization been carried out on this job, better use might have been made of them. In their Paper the Authors had themselves said initially that a soil-cement base would have effected economies. It would be interesting to hear more about this, for the use of a soil-cement base with asphalt on top was dismissed initially on account of the climatic conditions, although it was the very method of construction adopted in the end.

\section{Written contributions:}

Mr R. A. P. Berry (Ministry of Public Buildings and Works) said that during the discussion several questions were asked about the 1.c.n. system. As he was concerned with testing airfield pavements he thought some comments might be appropriate though he stressed that his comments were personal and did not necessarily represent the official views of the Ministry. 
154. As part of the process of developing the 1.c.n. system 10000 repetitions of loading on flexible pavements were actually made. Special equipment was devised to carry out the repetitions automatically, and this equipment was still in use for routine testing and occasional experimental work. Large numbers of repetitions had also been made on rigid pavements.

155. Testing was not carried out on new asphalt pavements because it had been found that the plate pressed into the surface and low strengths were measured. Kinks in the 10000 repetition graph were sometimes noted when testing thick asphalt pavements, and the graph tended towards a curve at higher loads, though these loads usually proved to be over the safe load evaluated for the pavement. When plotting the graph, the third, fourth and fifth points were used for estimating the deflexion at 10000 repetitions; the first and second points were usually ignored.

156. It was known that temperatures affected the strength measured on a flexible pavement, but it had not yet been possible to carry out detailed tests to ascertain the actual effect. The temperature was measured at the time of testing, and account was taken of it when deciding the appropriate l.c.n. to allocate to the pavement after analysing the test results. The 1.c.n. was decided by an experienced engineer after a full consideration of the pavement construction, history and usage in addition to analysis of the test results: it was not merely the answer produced from a mathematical exercise on the test results.

157. For long-term use, Marshall mix asphalt was always recommended for pavements which had to take tire pressures greater than $1501 \mathrm{~b} / \mathrm{sq}$. in. B.S. 594 asphalt when aged had been known to take high tire pressures without failure, but this could not be guaranteed.

158. The 1.c.n. system was detailed in the Ministry Technical Publication 109 and in the ICAO Aerodrome Manual Part 4 (1st edition), Part 2 (2nd edition). ${ }^{7}$ The techniques of testing and evaluation had changed quite a lot since these publications came out, and it was hoped to issue a new edition later in 1967. This would include the accumulated experience in testing pavements at hundreds of airfields in Britain and overseas during the past twenty years. It would also give more detailed information about the method of testing and evaluating pavement 1.c.ns.

Mr E. H. Lewis-Dale (Department of Engineering, British Airports Authority). Referring to the method of evaluation of pavement strength (\$71-74, Fig. 15 and Table 9) the Authors correctly deduced that, in early test results, a small number of load repetitions could not be extrapolated in a straight-line relationship with the logarithm of the number of repetitions to an equivalent deflexion of $0 \cdot 20 \mathrm{in}$. at 10000 repetitions. Evidently a value of load must be deduced which would cause tolerable values of deflexions at a number of repetitions equivalent to the useful life of the pavement, whether this number be 10000 or more or less.

160. As it was impracticable to test to 10000 repetitions, some system of extrapolation must be used whether it was on a logarithmic or some other basis. If, as an alternative, a single load application/deflexion was used, it must similarly be related to a tolerable deflexion after many repetitions. On this basis the upper lines of tests in Fig. 15 must be regarded as giving values which would lead either to failure or to intolerable deformation in a short time, unless, of course, the pavement improved considerably in the meanwhile or unless delayed recovery characteristics could be shown to be much better than the recovery indicated in short period tests. Knight had shown that various authorities had used differing values of tolerable deflexions for flexible pavements, the variation being from $0.05 \mathrm{in}$. to $0.50 \mathrm{in}$. Some, including Burmister, favoured $0 \cdot 20 \mathrm{in}$. It was clear, therefore, that $\mathbf{0 . 2 0} \mathrm{in}$. was not an absolute value and, indeed, this had been well known for a long time.

161. It was suggested that, if Fig. 15 was typical, the evaluated results in Table 6 might be unduly high. A single load application causing $0 \cdot 10$ in. deflexion in Fig. 15 would give a sharply rising curve suggesting early failure. 
162. Though doubts were raised on the assessed 1.c.n. values for the pavements early in their life, it was not unsound to assume that pavements would attain higher values, and indeed their design value, in reasonable time, provided there was a certainty that they would not be overloaded in the meanwhile. It might be fortunate that there were no current civil aircraft giving l.c.n. values as high as 100 .

163. Reference to the original Paper had shown that the Authors had doubts about the 1.c.n. evaluation system, particularly in the load/contact area relationship. Single load tests, however, had established a remarkably close agreement with the l.c.n. assumption, i.e.:

$$
\left(W_{1} / W_{2}\right)=\left(A_{1} / A_{2}\right)^{0.44}
$$

There was, however, as might be expected, some scatter in the higher loads, which might well be partly related to the use of a single load application rather than a value based on repetitional loading.

164. The Authors' use of Marshall specifications for asphalt surfacing materials seemed to have been far sighted. Civil airliners had already used tire pressures up to $180 \mathrm{lb} / \mathrm{sq}$. in. or more and some of the next generation of civil aircraft would certainly have tire pressures exceeding $200 \mathrm{lb} / \mathrm{sq}$. in., for which normal specification asphalts would not be suitable.

Mr H. S. Bhatia (Principal Research Officer, Building and Road Research Institute, Kumasi, Ghana) wrote that the Paper presented interesting data on the earthworks and pavement of an international airfield. For a Paper primarily focussing attention on pavement design and materials, it would have been more advantageous if thelongitudinal soil profiles along the runway and the taxiway had been included, to give a clear picture of the subgrade conditions. This was essential in view of the statement made in $\S 9$ that the area revealed layers of soft materials. It would have been interesting to know what proportion of the area was covered by soft materials, as this could substantially affect the final design. Perhaps the Authors could give some idea of this.

166. Mr Bhatia was not in full agreement with the statement in $\S 9$, that the clay subgrade soils would become consolidated during construction. The curves in Fig. 2 indicated that the clays of the type encountered at Kuala Lumpur could take a very long time to complete their secondary consolidation. Since the permeability of these clays was low, the consolidation process might take several years to complete. In cases where such clays covered large areas, the pavement would no doubt settle progressively with time (due to secondary effects). It might therefore be interesting to take levels regularly at different sections of the pavement, to observe the settlement characteristics of the subgrade.

167. Mr Bhatia also referred to Table 1 and Fig. 5 and considered that the clay fill and subgrade were of rather unusual characteristics. Although it did not have any coarse fractions, the soaked CBR values for the clay were abnormally high. For example, in bore hole no. 8 (depth $6 \frac{1}{2} \mathrm{ft}$ ) the unsoaked and soaked CBR values of the clay were $56 \%$ and $30 \%$ respectively. If this was so, why did the Authors not consider the use of such a material as a sub-base or level course instead of stabilized soil? In fact, the data indicated that such a material was good enough to be used as a sub-base without binders, thus economizing considerably on the cost of construction. Referring to Fig. 5 again, it could be seen that the CBR values of these clays obtained in the laboratory with 55 and 30 blows, using a $10 \mathrm{lb}$ rammer, were between $40 \%$ and $70 \%$. The activity of the clay was above $1 \cdot 5$, which would classify it as a minerologically active material, yet the soaked CBR values were abnormally high. The attainment of such high strength by a clay being rare, further studies to advance our knowledge on compacted clays of that type were needed. It could further be noted in Fig. 5 that the CBR values below and at optimum moisture content were very much higher than the values when the clay was compacted above optimum moisture 


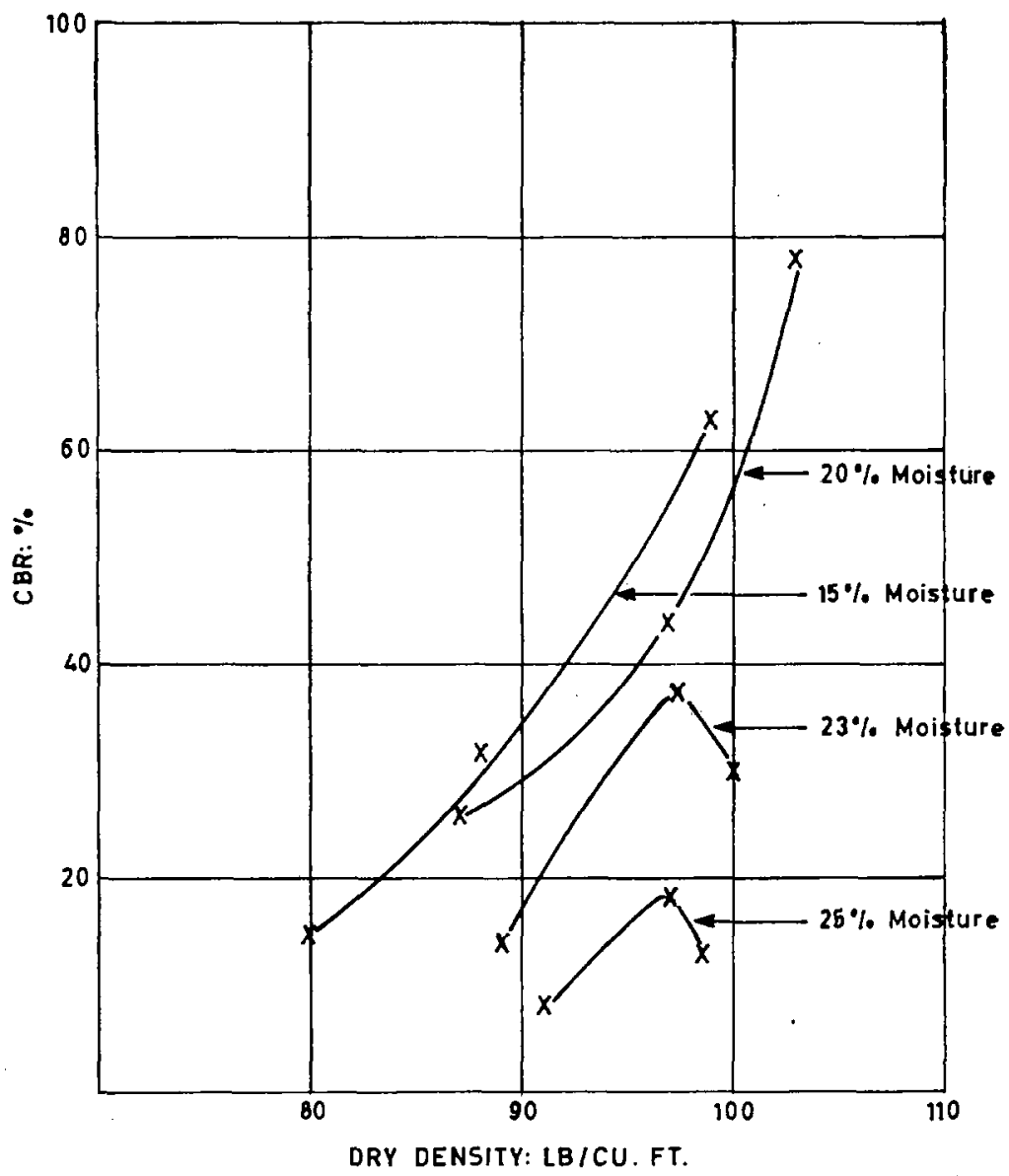

Fig. 17: Effect of increasing densities on the CBR values of Kuala Lumpur CLAY (interpolated from Fig. 5)

content. It would therefore be interesting to know from the Authors why they did not consider making use of the intrinsic strength of the clay, but accepted instead a CBR value of only $10 \%$, for pavement design. This meant that they made use of only $\frac{1}{6}$ of the strength of clay for design purposes. Did the Authors not consider it worthwhile to bring down the moisture of the clay to between $15 \%$ and $22 \%$ at the time of compaction to get the best results? This could have been possible, especially for fills, considering that a large shed was provided on the site for air-drying the soils. Once this could be achieved the pavement thickness could be designed on CBR values of at least $30-40 \%$, instead of $10 \%$.

168. Another point which needed careful consideration in the compaction of clays was that increasing densities did not necessarily increase their strength. This also applied to the clays under discussion, especially at moisture contents above $23 \%$. 
That was in fact the moisture at which the Authors expected a CBR value of $10 \%$. To illustrate the point, if in Fig. 5, say at a moisture content of $25 \%$, various densities and their respective CBR values as obtained in the three compaction curves were plotted, a relation between density and CBR for a moisture content of $25 \%$ was obtained. Such relations for moisture contents of $15,20,23$ and $25 \%$ as interpolated from Fig. 5, were shown in Fig. 17. It would be seen that at $25 \%$ moisture the effect of higher compaction was rather deleterious to the strength. This phenomenon could have far-reaching effects on the stability of an airfield pavement where the compaction standards were usually high. One could see from Fig. 17 that the best effects of increasing compactive energy could be obtained in the clay at or slightly below optimum moisture contents, and this point needed consideration for clay subgrades and fill materials.

169. Mr Bhatia also felt that use of Burmister's curves for the design of airfield pavements could lead to errors. The field experience on which the US Corps of Engineers design curves and the 1.c.n. method were based was considerable, and that experience at the moment could not be claimed by any other design method. The Authors, in using Burmister's curves, had been able to get about $50 \%$ reduction in the thickness of the pavement, as obtained from l.c.n./CBR curves or US Corps of Engineers curves. This reduction was a little too high. Even in soil-cement where the rigidity of the material was considerable when compared to soil-bitumen, a reduction of pavement thickness of about $30 \%$ was suggested by the British practice. There seemed to be no doubt that upper layers of soil-bitumen construction at Kuala Lumpur would stand effectively the stresses imposed by the wheels of the heaviest types of aircraft. However the thickness might not provide sufficient cover on the subgrade with a CBR value of $10 \%$, to reduce the stresses to a safe limit.

170. The remarks on the economy of soil-bitumen construction $(\$ 23)$ were not very convincing. It would have been appropriate if the unit cost of various types of construction on the site could have been given. It might be interesting to know how much more economical stabilized soil could be, when compared to soil-bitumen. The argument that soil-cement construction was not finally considered practical on account of bad weather was equally applicable to soil-bitumen construction. In fact bad weather could affect the quality of soil-bitumen construction far more than the cement- or lime-stabilized soil construction.

171. Mr Bhatia finally remarked that knowledge on airfield design and the use of various materials in the tropics was still very limited and congratulated the Authors on producing a paper of this nature. He hoped that it would act as a stimulant for further work in this very important field.

The Authors, in reply, referred to Dr Millard's request for more information on the control of earthwork compaction. The soil under pavement areas was laid in layers of 6 in. compacted thickness. The thickness of the layers of fill was checked for each layer by levelling on a $100 \mathrm{ft} \times 100 \mathrm{ft}$ grid. Densities and moisture contents of soil samples were checked on the same grid and if below the specified $95 \%$ B.S. heavy compaction density, compaction was continued until this density was achieved. The Client paid only for the successful density and moisture content tests. On achieving the specified density the area was approved for the spreading of the next layer of fill. If it rained before the next layer of fill was compacted the approval of that layer and the layer below was withdrawn and the Contractor had the choice of either removing the wet soil or discing, drying and compacting the layer until this and the lower layer which was retested achieved the specified density.

173. The effect of monthly rainfall on working hours could not really be seen from statistics, as the distribution of the rainfall had as great an effect as the total, but the recorded figures were given in Table 8 for earthmoving plant.

174. Table 1 gave details of the variation in the in situ moisture content with depth and from this table it would be observed that the average in situ moisture 


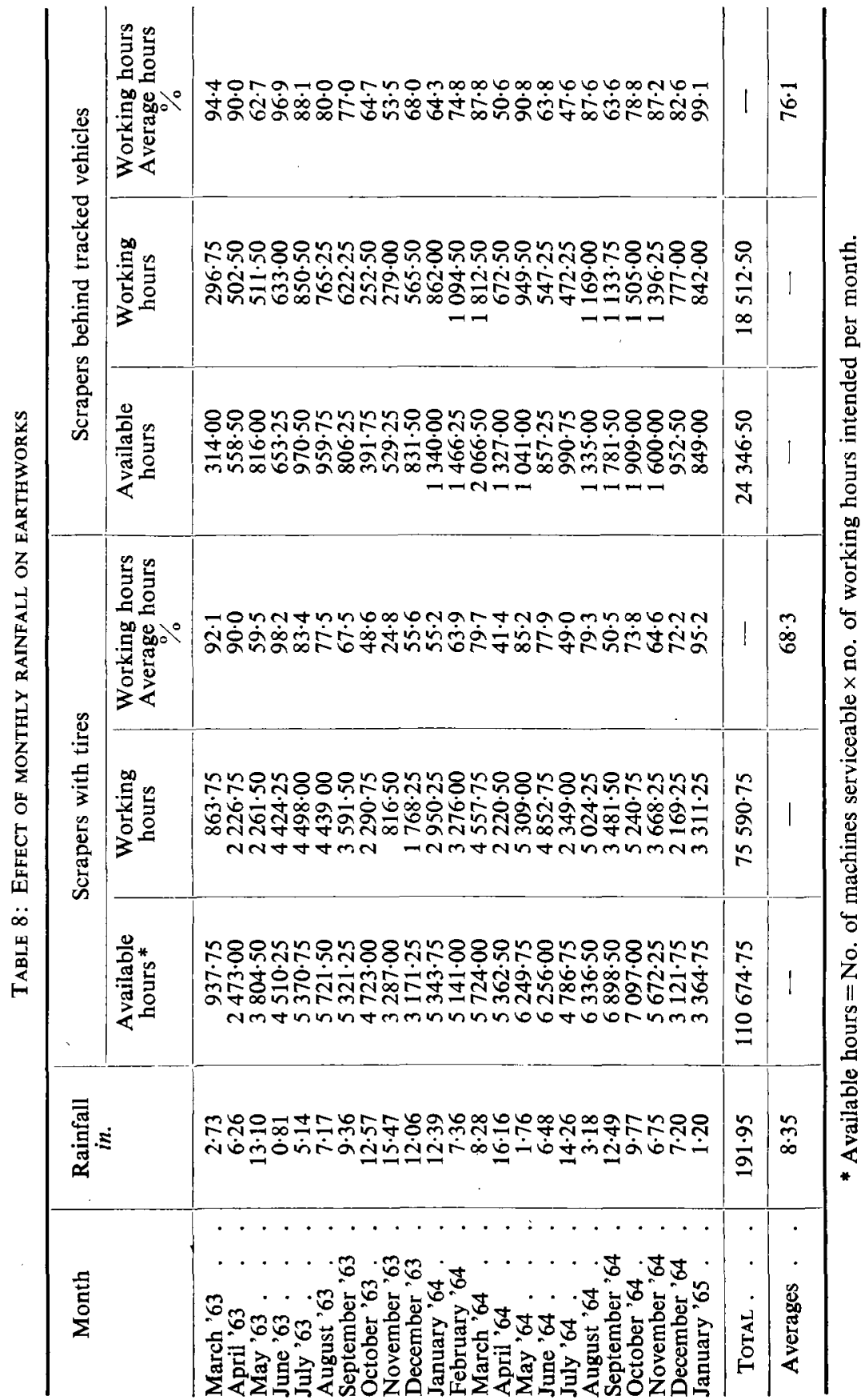


content was approximately the same as the average soaked moisture content in the CBR tests. As stated in the Paper, the criterion adopted for assessing the CBR of the subgrade was the arithmetic mean of the test results minus one standard deviation. As Table 1 showed, this gave rise to values of $14 \%$ and $12 \%$ for the optimum moisture content and soaked moisture content respectively. Perhaps either of these values could have been adopted, but in view of the experimental nature of the pavement and the small number of tests on which the design had to be based the slightly more conservative value of $10 \%$ was assumed.

175. With the time and equipment available on this contract the 4 in. depth of lime-stabilized soil was probably the optimum depth which could have been constructed.

176. The output of lime-stabilized soil was only possible because of the use of the mixing shed, which was used to its full capacity. Had single-pass multi-rotor machines been available it might have been possible to construct a deeper limestabilized soil course in situ. In the circumstances, remembering that the Contractor at tendering was only committed to the 4 in. working course in stabilized soil, it would not have been possible to construct 8 in. of stabilized soil in the time.

177. It was quite true that water did collect in the asphalt base, but it was allowed to drain off before the concrete edges were cast. Nevertheless the Authors had been surprised by the quantity of water seen to drain out of the bitumen-bound base course.

178. Mr Martin had pointed out that the pavement evaluation was not carried out in the accepted ICAO manner. In fact, tests were carried out in accordance with the accepted procedure but were interpretated in a different way when it was found that safe loads could not be interpolated properly. The procedure adopted for evaluation in the meantime was similar to that applied by Mr Martin himself." Mr Martin admitted that there was no record of such a thick new asphalt pavement being tested by the 1.c.n. system and it was suggested that this pavement might be considered as experimental, as was the one described previously by $\mathrm{Mr}$ Martin.

179. The full testing details could be obtained from the Authors, with the permission of the Director of Public Works, Malaya, but were too voluminous to include in the reply. Fuller information on these tests was available in the original full version of the Paper. The Authors would try to obtain a full record of the tests for the Library.

180. The effect of the sun on the lattice beam cantilever datum was not considered significant as it was always in the shade of the kentledge, and the daily shade temparature variation in Malaya was not great.

181. It was not suggested that the tests recorded in Tables 4 and 6 were used for control purposes. These were carried out to aid the assessment of the adequacy of the pavement design during the course of the construction, as stated in $\$ 59$ and 77. The more usual density and Marshall strength measurements were used for control purposes and these were recorded in Table 5.

182. Mr Jennings's description of the MPBW method of adjusting the bitumen content for aggregate over 1 in. size was interesting. The method used at Kuala Lumpur was to reduce the bitumen content in proportion to the reduced surface area of the aggregates in the mix. The whole philosophy of extracting the 1 in. and over aggregates from Marshall tests was arbitrary, since the mix then tested was not the one used in construction. It was suggested that there was a need for considerable development of the Marshall method for mixes with over-size aggregate.

183. A great deal of time was spent at Kuala Lumpur trying out different rolling sequences, but it was still not possible to achieve on average the desired density.

184. Mr Finnigan and Mr Bhatia had questioned the high soaked CBR values for this soil. These high values had been recorded from a great number of tests on residual granite soils in Malaya. It should be remembered that the plasticity index was measured only on material passing the B.S. 36 sieve. Another factor that could be of influence was the cubic shape of the quartz sand grains which formed over $40 \%$ 
of the soil. Perhaps it was the overall grading rather than the amount of any particular size that affected the soaked CBR values.

185. The manner in which the CBR of the subgrade was assessed had been given in reply to Dr Millard's question and the Authors felt, on the basis of the results achieved in the field, that the value of $10 \%$ was a fair choice.

186. In assessing the effects of the two equivalent single wheel loads considered at surface pressures of $100 \mathrm{lb} / \mathrm{sq}$. in. and $250 \mathrm{lb} / \mathrm{sq}$. in. the pressures were plotted against depth assuming a Boussinesq form of distribution in an isotropic material. The two curves thus produced crossed over at a depth of approximately $16 \mathrm{in}$. It would appear to be pure coincidence that this depth coincided with the depth of pavement assumed.

187. The runway was given a crowned profile with the recommended maximum cross falls of $1.5 \%$. The taxiways were given the same crossfall but were side-hung.

188. Presumably the MPBW designed for the effects of military jet aircraft on pavements which generally gave rise to more severe blast effects than did civil jet aircraft. It was not thought necessary to give special treatment to the ends of the runway.

189. In reply to Mr Mitchell, the price of hot bulk supply bitumen during the period of this contract was $114 /$ ton. The price of bulk supply cement was reduced from $£ 9.6 /$ ton to about $£ 6.4 /$ ton during the period of the contract. The price of lime which the Contractor produced himself was about $£ 5 \cdot 8 /$ ton. The epoxy-bitumen surface dressing was supplied by Shell International Petroleum Co. Ltd.

190. The manufacturers of the Hyster tamping roller recommended 15 miles/h as the most effective speed. It was in fact not possible to achieve this with the tractors used, and the rollers were operated at 11 miles/h. During an initial trial compaction test a tamping roller was towed by a crawler tractor at low speeds and was found to be ineffective. The vibration of the roller at the higher speeds seems to be important.

191. Lime was produced on the site from limestone quarried 25 miles away using the rubber timber for fuel. Eight $11 \mathrm{ft}$ dia. brick-lined cylindrical kilns $14 \mathrm{ft}$ deep were constructed on a sloping site giving access on one side at the top level for loading and on the other side at the bottom for fuelling and removing the burnt lime.

192. The burning of lime was carried out in the manner traditionally used by the Chinese, in which a dome was constructed of limestone blocks at the bottom of the kiln above the hearth. More limestone blocks were carefully laid by hand over the dome until the kiln was full with larger blocks at the bottom forming the dome and progressively smaller pieces above. The hearth was filled to a depth of $4 \mathrm{ft} 6 \mathrm{in}$. with dry wood and the entrance to the hearth partly bricked-up, but leaving ventilation holes and a square opening of about $2 \mathrm{ft} \times 2 \mathrm{ft}$ for refuelling. The kiln was fired and stoked for 72 hours. It was allowed to cool for a further 48 hours with the ventilation holes closed, after which the bricked-up entrance was knocked down and the ash in the bottom of the hearth covered with iron sheets. Within a few hours the burnt lime in the dome became partly slaked in the humid air and the dome collapsed.

193. The partly slaked lime was then removed and placed in a large shed where the air slaking continued until it was a fine powder. At this stage the Contractor departed from tradition and collected the powdered hydrated lime by a sunction hose, passing it through a cyclone extractor from where the material of less than B.S. 100 sieve was pumped into silos. By this method one kiln produced about 30 tons of lime per burning and used about 60 tons of rubber wood. Each kiln could be fired every eight days.

194. With reference to Mr Mitchell's comments on the higher 1.c.n. for pavements with cement-stabilized working courses it should be remembered that these areas also had sand fills and the subgrades were therefore very good. The rate of gain of strength of the lime-stabilized soil was less than that for cement-stabilized soil but continued for much longer. No soil suction tests were carried out prior to design of the pavement but before the Authors left Malaya they asked that cores be cut from 
the runway at various intervals of time and the equilibrium moisture content under the pavement determined.

195. On this contract and on other projects in Malaya the Authors had experimented with bitumen-stabilized sands. Whilst they had proved suitable for certain road projects they did not prove acceptable for airport pavements. A Marshall stability of $650 \mathrm{lb}$ had quite frequently been used on the Continent and in America as Mr Nutt had noted. The pre-tender experiments included unsuccessful tests on sand mixes and the Contractor also experimented with sand only for the bitumenbound base course, but the bitumen and filler contents required to satisfy the Marshall specification were too high to be economical. The rolling techniques for the asphalt work had been described in another paper. ${ }^{5}$

196. The pavement was designed to accommodate tire pressures up to $250 \mathrm{lb} /$ sq. in. but use by military aircraft was not envisaged. Among the other reasons considered for adopting the Marshall method of design were the ease, simplicity and accuracy with which control testing could be carried out.

197. The location of the terminal building was largely determined by the fact that the better soil conditions were found at the southern end of the site. Wind conditions were not significant. In the type of aircraft which would mainly use the airport the taxiway configuration allowed landing and take-off operations in both directions without unduly long taxi-ing distances. Other factors which had to be considered when locating the terminal building were the physical restrictions imposed on the site by a road on the western side and the Sungei Damansara to the east. These restrictions also had some bearing on the. depth of apron possible.

198. Until results were in hand of the tests which were to have been carried out after the runway had been in operation for about 12 months, it would not be possible to make a dogmatic comment on Mr Turner's remarks on whether the design was proved or not. Whilst the Authors had reservations about the use of Burmister curves for general design purposes they did feel that the tests carried out prior to publication of the Paper indicated that the strength of the pavement was increasing with age and would attain a sufficient strength to justify the design.

199. Mr Turner was right in not considering the limestone as a local material and in fact only a few hundred tons of limestone were used to supplement the granite used for the bitumen-bound base course and the binder course. Had they known before the work started of the existence of this deposit of a course sand within scraper range of the airport it was possible that a cement-stabilized base course would have been adopted but as things turned out to have done so would have delayed the completion of the pavements.

200. Mr Berry's contribution was appreciated as it went a long way to confirm what was concluded after the initial 1.c.n. testing at Kuala Lumpur.

201. A completed description of the 1.c.n. pavement testing method as described by Mr Berry in $\S 158$ would be of tremendous assistance for those other than members of the MPBW who had to apply it. This would be especially so if it could bring out the full range of the Ministry's experience, including that of testing unconventional pavements, because it was in cases where the results did not follow the same pattern as that of a conventional pavement that the engineer had to make his own adjustments to the 1.c.n. system in order for it to make sense. If this practice continued the 1.c.n. would cease to be a standard method of assessing the strength of an airport pavement.

202. Mr Lewis-Dale's discussion on what constituted a tolerable deflexion was very valid but in a way a complication to making the 1.c.n. system applicable to all types of flexible pavements. A tolerable deflexion on a completely asphalt pavement such as the one at Kuala Lumpur might be intolerable on a largely cement- or limestabilized soil pavement. It had rightly been pointed out that this runway could not in the meantime be loaded to an 1.c.n. of 100 because no aircraft using it were to that 1.c.n. Now that the pavement was over 18 months old another evaluation was in progress but the details of it were unfortunately not yet available to the Authors. 
203. The volume of soft material excavated from below pavement areas amounted to about $50000 \mathrm{cu}$. yd or approximately $1 \%$ of the fill.

204. Mr Bhatia had suggested that the pavement would continue to settle for some time after construction. Calculations on settlement for material at the north end showed that $90 \%$ of the settlement would take place within 18 months, which was within the construction period for fill materials. It was not likely that secondary effects would be significant with the clay subgrade soils, as the material was a sandy silty clay and not a pure clay. A careful check of levels on the pavements carried out at the end of 1966 showed no measurable settlement in the 18 months since completion.

205. Mr Bhatia has asked why the compacted soil was not used as a working course. It was essential to have a firm, dry and fairly rigid working course to be able to compact the first layer of asphalt. Although the soaked CBR values were good, these were measured on confined soil under a surcharge load, not directly under traffic. The rutting which traffic would cause in wet weather would require the surface to be scraped off and this would make it extremely difficult to keep to the correct level and inevitably require an unintentional increase in depth of the base course.

206. Moisture contents of $20 \%$ and $21 \%$ were achieved only with difficulty. It was inconceivable that a moisture content of $15 \%$ could be consistently reached with these soils in the Malayan climate. The drying shed was inadequate for the limestabilized soil mixing requirements and the suggestion that it be used for drying the subgrade fill as well was out of the question.

207. This raised a point that had not been mentioned, which was that adding lime to clay considerably increased the drying-out rate for the clay.

208. A study of Table 1 would show that the in situ moisture contents were similar to the soaked values used in the CBR tests and the reasoning for the choice of CBR $10 \%$ was given in reply to Dr Millard's question.

209. The Authors agreed that Burmister's curves needed very careful interpretation but did not agree with the percentage reduction in pavement thickness quoted by Mr Bhatia. They did feel, however, that the percentage reduction suggested by British practice was rather on the conservative side.

210. Mr Bhatia seems to have fallen into the same error as other contributors in his assessment of the reasons given for the type of pavement chosen. The limestabilized soil construction programme was seriously handicapped by the weather and the programme was only completed in time by the employment of the methods discussed in the Paper.

211. The price of the 12 in. thick bitumen-bound base course was $17 s 6 \mathrm{~d} / \mathrm{sq}$. yd laid, and that of the 4 in. thick lime-stabilized soil $3 s 3 d / s q$. yd. The aggregates for the asphalt were batched and dried and the mixing was quite unaffected by the weather. The asphalt could be laid as soon as the sealed wearing course or lower asphalt layer was dry after rain. As could be seen in Fig. 16, the monthly rainfall had little effect on that part of the work, but the effect on stabilized soil output was considerable.

\section{REFERENCES}

4. Martin F. R. A heavy-duty airfield pavement embodying soil stabilization. Proc. Instn civ. Engrs, 1957, 6 (April) 612-639.

5. Rook H. Pavement design and construction. Shell Bitumen Rev. Special Supplement on Kuala Lumpur Airport, 1966, 22 (Jan.) 6-14.

6. MCLeod N. W. Economical flexible pavement design developed from Canadian runway study. Engineer, 1949, 142 (April 28; May 12; May 26; June 9).

7. Aerodrome Manual, Part 2: aerodrome physical characteristics. International Civil Aviation Organization Doc. 7920-AN/865/2/Part 2. 2nd edition, 1965. 